\title{
A primazia do conhecimento intuitivo diante do conhecimento abstrato em Schopenhauer
}

\author{
Daniel Ramos dos Santos \\ Mestrando em Ética e Epistemologia pela UFPI/Bolsista da CAPES
}

RESUMO: O objetivo aqui será o de mostrar a importância que a noção de entendimento adquire na teoria do conhecimento de Schopenhauer. Tal noção, como será mostrada, tem como base a unidade representativa, possibilitada pela inter-relação entre sujeito e objeto. Será utilizado aqui como principal referencial teórico o livro I de $O$ mundo como vontade e como representação do filósofo em questão, além de textos de comentadores relacionados com o tema aqui abordado. Com base no que foi pesquisado chegou-se a conclusão que o papel do entendimento, tal como Schopenhauer o descreve, é de fundamental importância para o conhecimento, sendo que, nesta perspectiva, a razão, ou conhecimento abstrato, adquire um papel secundário, a saber, o de formulação de conceitos, de modo que seria impossível a existência de conhecimento abstrato sem o conhecimento intuitivo possibilitado pelo entendimento, mas o contrário sim seria possível.

PALAVRAS-CHAVE: entendimento; representação; conhecimento intuitivo; conhecimento abstrato

ABSTRACT: The aim here is to show the importance that the notion of understanding acquires in the theory of knowledge of Schopenhauer. This notion, as will be shown, is based on the unit representative, made possible by the interplay between subject and object. Will be used here as main reference the book I of The World as Will and representation of the philosopher in question, beyond will used texts of commentators related with the subject approached here treaty. Based on what was searched was reached the conclusion that the role of understanding, as Schopenhauer describes it, is of fundamental importance to knowledge, and, in this light, reason, or abstract knowledge, takes a secondary role, the namely the formulation of concepts, so it would be impossible the existence of abstract knowledge without the knowledge made possible by the intuitive understanding, but rather the opposite would be possible. KEYWORDS: understanding, representation, intuitive knowledge; abstract knowledge

\section{Introdução}

O objetivo aqui será o de mostrar a relevância do entendimento para a teoria do conhecimento de Schopenhauer. No início do texto, no item dois, será feita uma breve apresentação de sua filosofia - apenas a título de contextualização para melhor localizarmos a questão a ser tratada aqui - expressa em sua principal obra, O mundo como vontade e como representação.

$\mathrm{Na}$ primeira parte dessa obra Schopenhauer aborda o mundo apenas sob um aspecto, a saber, ele toma o mundo como sendo apenas representação. Na segunda parte ele chegará à concepção do mundo como sendo também vontade, a qual seria responsável 
pelo sofrimento no mundo. As duas últimas partes serão uma tentativa de aplacar esse sofrimento, tendo como mote principal a negação da vontade como forma de levar a termo o sofrimento da humanidade. Todavia, o nosso foco estará voltado aqui apenas para o mundo como representação, assunto abordado por Schopenhauer na primeira parte da obra acima citada, posto que nosso tema a ser tratado é a teoria do conhecimento e o objeto conhecimento é a representação.

Em seguida, ainda no tópico dois, faremos uma exposição do ponto de partida da teoria do conhecimento de Schopenhauer. Ele afirma haver uma verdade que é válida para todo o ser que conhece, e que sendo assim, serve de pressuposto para todas as outras. Esta verdade seria a de que 'o mundo é minha representação'. Na base dessa verdade estaria a divisão sujeito e objeto. Seriam eles os elementos responsáveis pela unidade representativa que, ao que parece, serve de ponto de partida para a teoria do conhecimento do filósofo aqui em questão.

No item três, será feita uma breve exposição do princípio de razão suficiente de Schopenhauer, por entender que tal princípio é de fundamental importância para o entendimento daquilo que pretendemos abordar aqui que é a sua teoria do conhecimento. Este princípio, como veremos, divide-se em quatro raízes que correspondem a quatro classes de representações. A primeira raiz é a do devir, a segunda é a do conhecer, a terceira é a do ser e quarta é a do agir. É o princípio de razão, como veremos, que une todas as classes das representações, é o vínculo comum entre elas.

Por fim, no item três, após apresentados os pressupostos da teoria do conhecimento schopenhaueriana, entraremos no escopo da questão, a teoria do conhecimento propriamente dita, onde se apontará para a relevância do entendimento frente à razão, de acordo com a perspectiva de Schopenhauer.

\section{A unidade representativa}

A filosofia de Schopenhauer está dividida em quatro partes bem definidas em sua principal obra, O mundo como vontade e como representação. Na primeira, ele realiza um ataque à filosofia idealista transcendental kantiana, sustentando não haver realidade em si, mas apenas representações. Na segunda, ele chega à descoberta de seu princípio metafísico, 
a Vontade, como realidade última, ou como coisa em si mesma, da qual o mundo e a vida são representações. Tomando por base o princípio da Vontade como realidade última que nos impulsiona para as ações, e entendendo essa pulsão como totalmente cega e não-teleológica, chega-se à conclusão de que viver é sofrer, pois em nossa vida enfrentamos uma série de desejos advindos da vontade, e uma vez manifestados em nós esses desejos - e eles sempre se manifestam, e infinitamente - o que temos ou obtemos no presente, como uma tentativa de satisfazer o desejo manifestado, é sempre insuficiente, pois sempre que satisfazemos um desejo surge imediatamente outro e assim sucessivamente. O presente é insuficiente, o futuro, duvidoso, e o passado irreversível, logo, sofrimento.

As duas outras partes da obra de Schopenhauer em questão representam justamente uma tentativa de aplacar esse sofrimento. Para tanto, já que é a Vontade toda a fonte deste, então, a única saída será a negação da mesma, mas isso não é possível, o que podemos fazer é tentar impedir que ela se objetive em nós, e ao que parece, é disso que irá se ocupar a ética de Schopenhauer. O mundo, de acordo com Schopenhauer, é constituído por duas partes, representação e vontade. Nossa preocupação aqui será o mundo como representação, pois é aí que se encontra a teoria do conhecimento ou a teoria da representação em Schopenhauer, presente no livro I de $O$ mundo como vontade e como representação.

Logo nas primeiras linhas do livro I da obra acima referida, Schopenhauer afirma que há uma verdade que é válida para todo o ser que vive e conhece. Uma verdade mais universal que qualquer outra, sendo que todas as outras já a pressupõem, a saber, que “o mundo é minha representação". Essa verdade vale para todas as classes de representações e embora valha para todos os seres, apenas o homem é capaz de trazê-la à consciência refletida e abstrata. O que está na base dessa verdade é, segundo Schopenhauer, a divisão sujeito e objeto. É só a partir dessa divisão que todas as classes de representações podem ser pensadas, pois é esta divisão a forma comum àquelas. Diz Schopenhauer:

Verdade alguma é, portanto, mais certa, mais independente de todas as outras e menos necessitada de prova do que esta: o que existe para o conhecimento, portanto o mundo inteiro, é // tão-somente objeto em relação ao sujeito, intuição de quem intui, numa palavra, representação. Naturalmente isso vale tanto para o presente quanto para o passado e o futuro, tanto para o próximo como para o distante, pois é aplicável até mesmo ao tempo, bem como ao espaço, unicamente nos quais tudo se diferencia. Tudo o que pertence e pode pertencer ao mundo está 
inevitavelmente investido desse estar-condicionado pelo sujeito, existindo apenas para este. $\mathrm{O}$ mundo é representação ${ }^{1}$.

De acordo com a teoria do conhecimento de Schopenhauer, deve-se sempre partir daquilo que é uma unidade representativa, do sujeito e objeto, e não de uma dessas partes isolada. Esta unidade representativa entre sujeito e objeto é proporcionada pelas diversas formas do princípio de razão suficiente da seguinte maneira: tais formas aplicam-se somente ao objeto e nunca ao sujeito, no entanto - o que realiza o liame - elas são conhecidas de modo a priori pelo sujeito, ou seja, são conhecidas pelo sujeito de modo totalmente independente dos objetos, ao contrário do que pensava Hume, quando defendeu que, por exemplo, o princípio de causalidade seria adquirido a posteriori, pelo hábito, o que nos levaria a crer numa regularidade da natureza que na verdade não há.

As formas de tempo, espaço e causalidade, as quais pressupõem a unidade representativa 'sujeito e objeto', só são aplicáveis aos objetos, mas, como acabou de ser dito, elas pressupõem sujeito e objeto, sendo assim, elas são o limite comum entre sujeito e objeto, e assim se estabelece a unidade representativa. Nesse sentido, de acordo com o que ficou entendido aqui, parece que não há objeto sem sujeito nem sujeito sem objeto. As leis do princípio de razão suficiente se aplicam ao objeto como representado e relativamente ao sujeito como representante, pois o objeto só é objeto enquanto para um sujeito. O princípio de razão pertence ao sujeito, mas somente pode ser aplicado aos objetos, por isso, há uma interdependência entre sujeito e objeto, consequentemente, não há aqui uma relação de causalidade do sujeito para com o objeto nem do objeto para com o sujeito, o princípio de razão suficiente em todas as suas diversas aplicações pressupõe a unidade representativa formada pelos dois, senão estaríamos fazendo uso do princípio de razão apenas em uma de suas aplicações ou raízes.

Diante do exposto, parece consentâneo que seja feita, mesmo que de modo breve, uma apresentação do princípio de razão suficiente elaborado por Schopenhauer antes de se falar de modo mais detalhado de sua teoria do conhecimento, é o que tentaremos fazer a seguir.

${ }^{1}$ SCHOPENHAUER, A. MVR I, $\S 1$, p.43 


\section{O princípio de razão suficiente}

O princípio de razão suficiente é o que une todas as classes de representações, é o vínculo comum entre elas. Pode ser expresso da seguinte maneira: 'tudo que é tem uma razão para ser'. É, este princípio, a forma dos objetos, e é a partir dele que se explicam todas as coisas que nos aparecem, porém não é ele mesmo passível de explicação, pois tentar explicar o princípio de razão suficiente seria cair em um círculo vicioso, sendo que requerer explicação ou fundamento para ele seria já pressupor a validade do princípio.

O princípio de razão suficiente subdivide-se em quatro raízes, correspondentes a quatro classes de representações, a primeira é a raiz do devir, o princípio de razão do devir. A causalidade, juntamente com as formas a priori da sensibilidade, espaço e tempo, formam esta raiz do princípio de razão. Schopenhauer não faz uma separação entre sensibilidade e entendimento. Espaço e tempo, as formas a priori da sensibilidade, são entendidas como presentes no entendimento juntamente com a causalidade que proporciona o vínculo entre essas duas formas. $\mathrm{O}$ entendimento com o mesmo caráter da sensibilidade recebe as sensações como um efeito e assim as vincula a causalidade para ir através do tempo até as suas origens e posicioná-las no espaço como representação intuitiva. E como diz Barboza, "a causalidade, ao vincular espaço e tempo no entendimento, possibilita, portanto a percepção (intuição empírica) do mundo" ${ }^{\text {. }}$. Esta raiz do princípio de razão é chamada de devir porque trata dos objetos da efetividade e estes estão em constante mudança, ao que parece, tal como entendeu Heráclito quando diz que "em um rio não se pode entrar duas vezes no mesmo" pois da segunda vez o rio e a pessoa seriam outros, donde a ideia de devir". Corroborando este ponto, Cacciola afirma que, "é diante do fluxo temporal que jamais se detém, levando consigo todos os objetos, que Schopenhauer, reconhecendo como idênticos a representação e o objeto, atribui a este uma existência meramente relativa" 4 .

A segunda raiz é a raiz do conhecer, ou o princípio de razão do conhecer. Este princípio rege a classe de representações abstratas, ou os conceitos. Enquanto que o

2 BARBOZA, J. "Way of aesthetic knowledge and world in Schopenhauer". In: Trans/Form/Ação. (São Paulo), v. 29(2), 2006, p. 36.

${ }^{3}$ HERÁCLITO, Fragmento 49a.

${ }^{4}$ CACCIOLA, M. L. Schopenhauer e a questão do dogmatismo, p. 29. 
princípio de razão do devir está presente em todos os animais, o princípio de razão do conhecer, até o que se sabe, só é encontrado nos homens, ou nos animais humanos. Os conceitos são representações de representações e são formados a partir do entendimento, sendo assim, por mais abstrato que seja o conceito, ele só é possível, ou só tem seu início, por conta do entendimento ou da sensibilidade, já que Schopenhauer não faz separação entre ambos. E como diz Barboza, “a razão decanta as intuições e obtém representações de representações, exatamente os conceitos, os quais, ligados entre si, formam juízos"

A terceira raiz do princípio de razão corresponde ao princípio de razão de ser. Este terceiro princípio rege uma terceira classe de objetos, a saber, aqueles sem os quais as representações não seriam possíveis, a parte formal de toda e qualquer representação, o espaço e o tempo. Aqui eles são tomados isoladamente sem fazer referência à sua aplicação às intuições. $\mathrm{O}$ espaço e o tempo são as formas a priori do sentido interno e externo. $\mathrm{O}$ espaço e o tempo são, nesse sentido, a razão de ser de qualquer representação.

A quarta e ultima raiz do princípio de razão suficiente corresponde ao princípio de razão do agir. Este quarto princípio rege uma espécie de objeto que não pode ser representado, o sujeito do querer tornado objeto. Este princípio trata mais especificamente da "classe das ações que tem por base o representante em que se distinguem: motivos, estímulos, excitações". Ao observarmos a nós mesmos vemo-nos como pura vontade em diferentes graus, e aqui se vê que há algo que não pode ser tomado como objeto em sentido estrito, como representação, tal como nas outras figuras do princípio de razão, pois o que há aqui é a vontade, a qual serve de princípio para o agir, ou seja, é o princípio de razão do agir.

Posto isso, percebe-se que, para Schopenhauer, todas as representações, o mundo percebido, são regidas pelo princípio de razão suficiente. E este princípio, no entanto, tem como base fundamental a relação entre sujeito e objeto. Só há representação se houver quem as represente, e uma vez havendo um representante haverá representação, e tais representações para existirem pressupõem, como vimos, leis a priori, que, como tais, pressupõem o sujeito, mas que somente podem ser aplicadas aos objetos, sendo assim, deve-se partir do sujeito e do objeto, tomando-os como reciprocamente dependentes.

5 BARBOZA, J. "Way of aesthetic knowledge and world in Schopenhauer". In: Trans/Form/Ação. (São Paulo), v. 29(2), 2006, p.37.

${ }^{6}$ VECCHIOTTI, I. Schopenhauer, p. 12. 


\section{A importância do entendimento para a teoria do conhecimento na filosofia de Schopenhauer}

Como já dito no início, no livro I de O Mundo como Vontade e como Representação Schopenhauer irá abordar o mundo sob um viés unilateral, a saber, o mundo como representação, afirma ele: "apenas na medida em que é representação, consideramos o mundo neste primeiro livro"7 . É no segundo livro que ele irá introduz a noção de Vontade como constitutiva da outra metade do mundo, para daí chegar a concepção do mundo como também sendo Vontade, donde a ideia do mundo como sendo constituído de um lado pela Vontade e de outro pela Representação. Assim, o mundo como vontade e representação, a que refere o título de sua obra considerada por ele mesmo como a mais importante. Afirma ainda Schopenhauer: "pois assim como este [o mundo] é, de um lado, inteiramente REPRESENTAÇÃO, é, de outro, inteiramente VONTADE"8. Com quanto, vale lembrar que estas duas partes do mundo devem ser entendidas como as duas faces de uma mesma moeda, ou seja, como inseparáveis na constituição do todo do mundo. Dessa forma, toda a realidade, para Schopenhauer, só pode ser uma dessas coisas, vontade ou representação, e assim sendo, a coisa-em-si, tal como no sentido kantiano, não tem qualquer realidade "é uma não-coisa fantasmagórica, cuja aceitação é um fogo fátuo da filosofia"”.

Mais uma vez, como o assunto aqui é a teoria do conhecimento, o interesse estará voltado apenas para o mundo como representação, posto que seja neste que se dá todo o conhecimento submetido ao princípio de razão. Outro tipo de conhecimento possível para Schopenhauer, este independente do princípio de razão, seria o conhecimento artístico, porém, não será tratado aqui.

Segundo Schopenhauer, as formas de todo conhecer é o espaço e o tempo ${ }^{10}$. O sujeito, aquele que conhece, não está nessas formas, logo, ele não é e nem pode ser conhecido. Ele não se encontra nestas formas porque elas já o pressupõe, posto que, são dadas a priori para o sujeito. O mundo como representação, por sua vez, possui duas partes igualmente importantes, essenciais e inseparáveis, uma é o objeto, que tem espaço e tempo

${ }^{7}$ SCHOPENHAUER, A. MVR I, § 1, p. 44.

${ }^{8}$ SCHOPENHAUER, A. MVR I, $\S 1$, p. 45

9 SCHOPENHAUER, A. MVR I, § 1, p. 45

${ }^{10}$ SCHOPENHAUER, A. MVR I, $\S 2$, p. 45 
como forma, e a outra é o sujeito que não se encontra em tais formas, mas as contém em si aprioristicamente. As formas essenciais dos objetos são tempo, espaço e causalidade, e o princípio de razão é a expressão comum dessas formas a priori conhecidas a partir do sujeito. É aqui, então, que se dá o limite comum entre as duas partes essenciais do mundo como representação, entre sujeito e objeto.

Segundo Schopenhauer, a diferença fundamental entre nossas representações se dá entre as representações intuitivas e as representações abstratas. As intuitivas dizem respeito a todo o mundo visível, ou a experiência em sua totalidade junto com suas condições de possibilidade. As abstratas dizem respeito à classe das representações dos conceitos, ou as representações de representações, que como já foi dito aqui, fazem parte da capacidade que o animal humano tem - e apenas ele - de formular conceitos, ou seja, essa capacidade é a razão, e apenas essa seria a sua função.

Em se tratando das condições de possibilidade da experiência, ou das representações intuitivas, espaço e tempo, Schopenhauer afirma que é mérito de Kant a descoberta de que estas formas a priori da sensibilidade possam ser pensadas não só abstratamente, separadas de seu recheio, a experiência, mas que elas são, além disso, intuídas imediatamente. Assim sendo, tais formas serão entendidas doravante como intuíveis por si mesmas, independentes e antecedentes a experiência sensível, tanto que são condição de possibilidade de toda experiência sensível possível. Schopenhauer diz ainda que o tempo é a forma mais simples do princípio de razão. No constante devir do tempo, um instante só vem a ser quando aniquila aquele que lhe antecedeu, desse modo, passado e futuro são nulos, e o presente "é somente o limite sem extensão e contínuo entre ambos" "11. Esta mesma nulidade é reconhecida em toda variedade das formas do princípio de razão, o que faz com que tudo o que se encontre regido pelo princípio de razão tenha existência relativa. Por quanto, parece que, segundo esse ponto de vista, aquilo que está na base de todas as representações intuitivas é o devir advindo do tempo, a constante sucessão.

Dadas tais características temporais do princípio de razão de ser, princípio este que rege a classe das representações intuitivas, eis que o seu conteúdo, a saber, a matéria, tem como essência a causalidade ou o seu fazer-efeito, este é seu ser, e é desta forma que ela preenche o tempo e o espaço. Como afirma Schopenhauer:

\footnotetext{
${ }^{11}$ SCHOPENHAUER, A. MVR I, § 3, p. 48.
} 
Por conseguinte, o continente de qualquer coisa material é, de maneira bastante acertada, nomeado Wirklichkeit, efetividade na língua alemã, palavra muito mais significativa que Realität. Aquilo sobre o que faz efeito é de novo sempre matéria. Seu ser, toda a sua essência, portanto, consiste apenas na mudança regular que UMA das suas partes produz na outra, por conseguinte é por completo relativa, conforme uma relação válida só no interior de seus limites, portanto exatamente como o tempo e o espaço ${ }^{12}$.

A essência do conteúdo das formas a priori da sensibilidade, a matéria, obedece a uma determinação do tempo, pois o seu fazer-efeito implica sempre uma mudança que, por sua vez, é uma determinação temporal.

A matéria, ou a causalidade, só é conhecida pelo entendimento; é função exclusiva do entendimento conhecer a causalidade. O mundo efetivo, da causalidade ou da matéria, é intuído pelo entendimento, e a intuição do mundo efetivo pelo entendimento é o conhecimento da causa a partir do efeito, e sendo assim toda intuição é intelectual. Para sustentar essa afirmação, Schopenhauer elabora uma série de exemplos que ele considera irrefutáveis. Tais exemplos consistem em mostrar como o entendimento, por meio da causalidade, transforma, de uma só vez, meros dados em intuição propriamente dita. Um desses exemplos é o da visão singular apesar de ser realizada com dois olhos. Os dados são fornecidos através dos dois olhos, mas é o entendimento que se encarrega de tornar a visão singular, na transformação dos dados em intuição, por isso, "toda INTUIÇÃO não é somente sensual, mas também intelectual, ou seja, puro CONHECIMENTO PELO ENTENDIMENTO DA CAUSA A PARTIR DO EFEITO”"13.

\subsection{A crítica de Schopenhauer as filosofias que partem do sujeito ou do objeto}

Posto que a intuição é intermediada pelo conhecimento da causalidade pode-se chegar, segundo Schopenhauer, a um grande mal-entendido, o da crença na existência de uma relação de causalidade entre sujeito e objeto. Isso seria um mal entendido porque a relação de causalidade só ocorre entre os objetos imediatos e mediatos. Ele critica as filosofias que partem dessa pressuposição chamando-as de dogmáticas.

\footnotetext{
${ }^{12}$ SCHOPENHAUER, A. MVR I, § 4, p. 50.
}

${ }^{13}$ SCHOPENHAUER, A. MVR I, § 4, p. 55. 
O realismo parte da ideia de que o objeto é causa e o sujeito, efeito. Fazendo isso, o realista ignora que objeto e representação são a mesma coisa, concebendo assim algo impensável, um objeto-em-si. O ceticismo, para invalidar o argumento realista, parte da mesma separação entre representação e objeto, defendendo que, ao representarmos, conhecemos apenas o agir dos objetos, não o seu ser mesmo, afirmando ainda que não é necessário que haja qualquer semelhança entre eles. Nas palavras de Cacciola,

Tanto contra o realismo dogmático quanto contra o ceticismo adverte Schopenhauer: em primeiro lugar, a lei da causalidade não deriva da experiência; em segundo, objeto e representação não se distinguem; e, ainda, que o ser dos objetos é seu próprio agir (Wirken), já que matéria e causalidade são sinônimas ${ }^{14}$.

O idealismo fichtiano, tomado como exemplo por Schopenhauer, em sentido oposto, parte do sujeito, ou seja, faz do objeto um efeito do sujeito. Todavia, tem-se que sujeito e objeto precedem o princípio de razão suficiente e consequentemente qualquer experiência, é, portanto, condição de possibilidade desta, sendo assim, não pode haver uma relação de fundamento e consequência entre sujeito e objeto. O princípio de razão estende-se a todas as classes de objetos, mas ele não chega até o sujeito, e a controvérsia sobre a realidade do mundo exterior baseia-se justamente na ideia de que o princípio de razão estende-se até o sujeito, o que não é o caso, segundo Schopenhauer.

O conhecimento do objeto se restringe ao fazer efeito do objeto intuído. Dessa forma, o objeto é esgotado como objeto mesmo, como representação. Fora disso nada mais resta dele para ser conhecido. O mundo, nesse sentido, é causalidade pura, e é intuído no espaço e no tempo, o que o faz completamente real. A causalidade existe apenas no e para o entendimento, e assim sendo, o mundo efetivo, o mundo que faz efeito, é inteiramente condicionado pelo entendimento, e isto reforça a asserção de que o mundo é representação de um sujeito, e consequentemente, "é, sem exceção e em toda a eternidade, condicionado pelo sujeito, ou seja, possui idealidade transcendental" 15 . Dito isto, pode-se aqui inferir que a teoria do conhecimento de Schopenhauer caminha num viés transcendental. Em termos mais diretos, seria uma teoria do conhecimento idealista transcendental.

\footnotetext{
${ }^{14}$ CACCIOLA, M. L. Schopenhauer e a questão do dogmatismo, p. 30.

${ }^{15}$ SCHOPENHAUER, A. MVR I, § 5, p. 57.
} 
De acordo com o que foi exposto aqui, o entendimento tem uma importância fundamental para o conhecimento. É partindo dele que podemos intuir as representações, e as representações das representações, os conceitos, só são possíveis por causa do primeiro passo dado pelo entendimento, pois, como foi dito, são representações das representações que, por sua vez, são intuitivas, por isso, todo conhecimento começa por ele e só é possível por causa dele.

É por meio de nosso corpo que as intuições do mundo se dão em nós. É ele também uma representação intuída imediatamente, posto que é a representação que constitui o ponto de partida para o conhecimento. Há, por conseguinte, duas condições que tornam possível o conhecimento do mundo intuitivo, uma é o fato dos objetos serem capazes de fazerem efeito uns sobre os outros, ou seja, de realizarem mudanças, sem o que não seria possível qualquer intuição; a outra é a sensibilidade dos corpos animais, com a qual percebemos as mudanças nos objetos, e também sem esta obviamente não seria possível qualquer intuição. Em consequência, "cada força e lei natural, não importa onde se exteriorize, tem de primeiro ser conhecida imediatamente pelo entendimento, apreendida intuitivamente, antes de aparecer in abstractu para a razão na consciência refletida"16.

O conhecimento de causa e efeito é a forma a priori do entendimento, e está distribuído por entre todos os animais, humanos e não humanos. Como prova disso, Schopenhauer dá o exemplo de um filhote de cão que mesmo nunca tendo estado em situação semelhante antes, não se arrisca a pular de uma mesa, por mais que deseje fazer isso, pois ele consegue prever o efeito da gravidade de seu corpo. O entendimento, dirá ainda Schopenhauer, está inteiramente separado da razão, e assim como nos animais, no homem ele é também completamente irracional. Apesar disso, pode-se dizer que é toda condição de possibilidade da reflexão, "pois, de fato, esta é uma aparência refletida, algo derivado do conhecimento intuitivo e que, todavia, assumiu natureza e índole fundamentalmente diferentes, sem as formas do conhecimento intuitivo" (Ibidem, p. 82). O entendimento possui apenas uma função, o conhecimento imediato da relação entre causa e efeito, e a razão, por sua vez, também possui apenas uma função, da qual poderíamos dizer até que é secundária, a saber, a formação de conceitos. Dizer de alguém que é irracional ou

\footnotetext{
${ }^{16}$ SCHOPENHAUER, MVR I, § 6, p. 65.
} 
pouco racional, portanto, não é dizer que lhe falta entendimento, mas que lhe falta a habilidade para formar conceitos.

Posto isso, pôde-se perceber que, sob o ponto de vista de Schopenhauer, a intuição tem um papel primordial na aquisição de conhecimento, e que a razão tem uma posição secundária no mesmo processo. $\mathrm{O}$ mundo da reflexão tem o mundo intuitivo como seu fundamento. Em outros termos, as representações abstratas têm sempre como fundamento as representações intuitivas, ou seja, o fundamento do conhecimento das representações abstratas repousa sobre conhecimento das representações intuitivas, daí a importância da intuição para a teoria do conhecimento de Schopenhauer.

\section{Considerações finais}

Como vimos, a teoria do conhecimento de Schopenhauer toma como ponto de partida aquilo que ele chama de unidade representativa, que tem por base a divisão sujeito e objeto. Aquilo que é objeto do conhecimento, portanto, o mundo inteiro, é tão somente representação, na medida em que só há objeto em relação a um sujeito. Desse modo, o mundo só existe para o sujeito, posto que é representação, e só há representação se houver um sujeito representante. Sujeito e objeto formam, então, uma relação de codependência, eles não são a mesma coisa, mas os dois juntos formam uma unidade representativa. Esta unidade é mantida pelo princípio de razão, pois, este só pode ser aplicado aos objetos, mas pertence apenas ao sujeito, sendo assim, ele é o limite comum entre as duas partes.

O sujeito, para o qual o mundo é objeto, tem o entendimento como capacidade fundamental do conhecimento. É apenas por meio dessa capacidade, distribuída entre todos os animais, segundo a visão de Schopenhauer, que podemos intuir os objetos, - sendo que para ele entendimento e sensibilidade é a mesma coisa - consequentemente, o entendimento é peça imprescindível no processo do conhecer.

Portanto, como vimos, pretendeu-se destacar aqui a forma como Schopenhauer vê o entendimento e como essa noção adquire uma importância maior do que a atribuída à razão. Esta, restrita ao animal humano, seria apenas a capacidade de formular conceitos, os quais podem ser entendidos como representação de representação. A formulação de conceitos só é possível, então, por causa do entendimento, pois é este o responsável pela intuição das 
representações primárias e só há formulação de conceitos se houver tais representações. Dito de outro modo, só há representação 'de representação' se houver aquela primeira representação que é intuída pelo entendimento. Sendo assim, sem o entendimento o conhecimento em toda e qualquer modalidade não seria possível, enquanto que, havendo entendimento já teríamos conhecimento intuitivo. Isso mostra a dependência do conhecimento abstrato ante o entendimento, sendo que o conhecimento intuitivo é, então, condição de possibilidade do conhecimento abstrato.

\section{Referências bibliográficas}

BARBOZA, J. "Way of aesthetic knowledge and world in Schopenhauer". In: Trans/Form/Ação. (São Paulo), v. 29(2), 2006, p. 33-42.

CACCIOLA, Maria Lúcia M. O. Schopenhuaer e a questão do dogmatismo. São Paulo: EDUSP, 1994.

HERÁCLITO. “Fragmentos”. In: Vol. Pré-Socráticos, Col. “Os Pensadores”. Trad. de José Cavalcante de Souza. São Paulo: Nova Cultural, 2000.

SCHOPENHAUER, A. O Mundo como Vontade e como Representação. Tradução, apresentação e notas de Jair Barboza. São Paulo: UNESP, 2005.

VECCHIOTTI, I. Schopenhauer. Lisboa: Edições 70, 1990.

Recebido: 04/10/10

Received: 10/04/10

Aprovado: $20 / 11 / 10$

Approved: 11/20/10 